\title{
Penerapan K-Means Dalam Mengelompokkan Nilai Tambah Industri Besar/Sedang Menurut Kabupaten/Kota
}

\author{
Pika Aryani ${ }^{1}$, Ema Meyliza ${ }^{2}$ \\ Program studi Sistem Informasi, STIKOM Tunas Bangsa \\ aryanipika4@gmail.com ${ }^{1}$
}

\begin{abstract}
Each region must have industries both primary industries, secondary industries, manufacturing industries, construction industries, service industries and the quarter industry. These industries must produce an output that will be used or consumed by consumers or the public. More and more industries in a region indicates that the region has a lot of market demand from the community and the more industries, the income in the industry of a region increases. In this study the data was taken from a government website namely BPS (Statistics Indonesia) - www.bps.go.id which is a website that presents various statistical data from each region. There are 2 clusters in this study, namely high level clusters (C1) and low level clusters (C2). This study stopped at the 2nd iteration and there were centroid data generated namely high level centroid (78177, 56543, 42610, 155596) and low level centroid namely: ((3513.3), (3448.8), (2390.9) ), (4568)). From the calculation process that has been carried out there are 2 high-level districts / cities namely (Deli Serdang and Medan) and 31 other low-level districts / cities. It is hoped that this research can be input to the government in each region to inform the output data generated from industry in each region, and then the data can be used whenever needed.
\end{abstract}

Keywords: Datamining, Value-added, Clustering, K-Means, RapidMiner, Indonesia

\begin{abstract}
Abstrak
Setiap wilayah pasti memiliki industri baik itu industri primer, industri sekunder, industri manufaktur, industri konstruksi, industri jasa serta industri kuarter. Industriindustri tersebut pasti menghasilkan suatu keluaran yang dihasilkan dan akan di gunakan atau dikonsumsi oleh konsumen atau masyarakat. Semakin banyak industri di suatu wilayah maka menandakan bahwa wilayah tersebut memiliki banyak permintaan pasar dari masyarakat dan semakin banyak industri maka pendapatan di bidang industri suatu wilayah semakin meningkat. Di dalam penelitian ini data diambil dari sebuah website pemerintah yakni BPS (Badan Pusat Statistik) - www.bps.go.id yaitu website yang menyajikan berbagai data statistik dari setiap wilayah. Terdapat 2 cluster di dalam penelitian ini yaitu cluster tingkat tinggi (C1) dan cluster tingkat rendah (C2). Penelitian ini berhenti pada iterasi ke - 2 dan terdapat centroid data yang dihasilkan yakni centroid tingkat tinggi $(78177,56543,42610,155596)$ dan centroid tingkat rendah yakni: $((3513,3),(3448,8),(2390,9),(4568))$. Dari proses perhitungan yang telah dilakukan terdapat 2 kabupaten/kota tingkat tinggi yakni (Deli Serdang Dan Medan) dan 31 kabupaten/kota tingkat rendah lainnya. Diharapkan penelitian ini bisa menjadi masukan kepada pemerintah disetiap wilayah untuk menginformasikan data output yang dihasilkan dari industri setiap wilayah yang selanjutnya data tersebut bisa digunakan jika sewaktuwaktu dibutuhkan.
\end{abstract}

Kata Kunci: Datamining, Nilai Tambah, Klastering, K-Means, RapidMiner, Indonesia 


\section{Pendahuluan}

Setiap wilayah pasti memiliki industri baik itu industri primer, industri sekunder, industri manufaktur, industri konstruksi, industri jasa serta industri kuarter. Industriindustri tersebut pasti menghasilkan suatu keluaran yang dihasilkan dan akan di gunakan atau dikonsumsi oleh konsumen atau masyarakat. Semakin banyak industri di suatu wilayah maka menandakan bahwa wilayah tersebut memiliki banyak permintaan pasar dari masyarakat dan semakin banyak industri maka pendapatan di bidang industri suatu wilayah semakin meningkat. Di dalam penelitian ini data diambil dari sebuah website pemerintah yakni BPS (Badan Pusat Statistik) www.bps.go.id yaitu website yang menyajikan berbagai data statistik dari setiap wilayah. Tujuan penelitian ini untuk menganalisa apakah teknik ilmu komputer dapat diterapkan dalam mengelompokkan nilai tambah industri besar/sedang menurut kabupaten/kota sehingga hasil dari penelitian tersebut dapat menjadi informasi bagi pihak yang berkepentingan dalam mengambil kebijakan terhadap daerah yang memiliki nilai tambah industri. Tersedia banyak cabang ilmu komputer yang dapat kita gunakan untuk menyelesaikan permasalahan yang sifatnya kompleks. Cabang ilmu komputer tersebut adalah Artificial Intelligence seperti datamining [1]-[7], Sistem Pendukung Keputusan [8]-[21], sistem pakar [22], Jaringan Saraf Tiruan [23]-[26][27], [28], logika fuzzy [29] dan lain-lain. Salah satu ilmu computer yang dapat diterapkan dalam menyelesaikan permasalahan di atas adalah teknik datamining dengan metode klastering [30]. Penelitian ini menggunakan teknik datamining klastering dengan metode K-Means. Pada penelitian ini terdapat 2 cluster antara lain: cluster tingkat tinggi untuk pada nilai tambah industri besar/sedang (C1) dan cluster tingkat rendah pada nilai tambah industri besar/sedang $(\mathrm{C} 2)$.

\section{Metodologi Penelitian}

\subsection{Datamining}

Data mining juga bisa diartikan sebagai rangkaian kegiatan untuk menemukan pola yang menarik dari data dalam jumlah besar [31].

Berikut adalah flowchat dari K-means yang merupakan bagian dari datamining klastering seperti yang ditunjukkan pada gambar berikut:

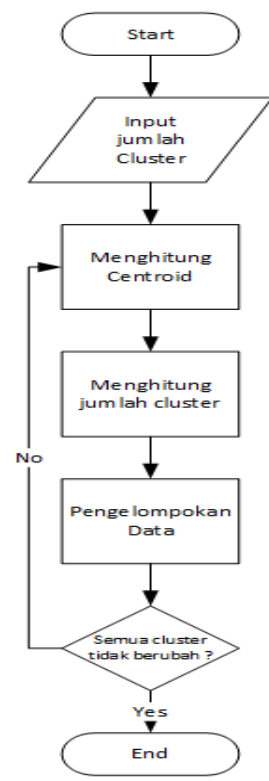

Gambar 1. Flowchat K-Means 


\subsection{Clustering}

Clustering adalah dapat digunakan untuk mengetahui struktur dalam data yang dapat dipakai lebih lanjut dalam berbagai aplikasi secara luas seperti klasifikasi, pengolahan gambar, dan pengenalan pola [4].

\subsection{Metode K-Means}

Pada dasarnya algoritma k-means hanya mengambil sebagian dari banyaknya komponen yang didapatkan untuk kemudian dijadikan pusat cluster awal, pada penentuan pusat cluster ini dipilih secara acak dari populasi data [6].

\section{Hasil dan Pembahasan}

Dalam melakukan clustering, data yang diperoleh akan dihitung nilai rata-rata terlebih dahulu agar lebih mudah dalam pengolahannya seperti yang dapat dilihat pada table 1 .

Tabel 1. Data Jumlah nilai tambah industri besar/sedang menurut wilayah (Milyar)

\begin{tabular}{|c|c|c|c|c|c|}
\hline No & Kabupaten/Kota & 2013 & 2014 & 2015 & 2016 \\
\hline 1 & $\mathrm{Ni}$ a s & 0 & 0 & 0 & 0 \\
\hline 2 & Mandailing Natal & 1304,07 & 1742,7 & 1629,39 & 2152,08 \\
\hline 3 & Tapanuli Selatan & 1065,5 & 916,73 & 1134,12 & 1076,04 \\
\hline 4 & Tapanuli Tengah & 980,93 & 888,08 & 939,23 & 2797,71 \\
\hline 5 & Tapanuli Utara & 163,72 & 413,49 & 343,93 & 645,62 \\
\hline 6 & Toba Samosir & 804,59 & 1352,88 & 1226,78 & 2797,71 \\
\hline 7 & Labuhan Batu & 4583,01 & 5191,18 & 4196,1 & 5595,42 \\
\hline 8 & As ah an & 7057,51 & 9343,39 & 7483,84 & 29914 \\
\hline 9 & Simalungun & 7142,76 & 6414,33 & 6038,57 & 12266,9 \\
\hline 10 & $\mathrm{D}$ a i r i & 59,52 & 59,81 & 0 & 645,62 \\
\hline 11 & $\mathrm{~K}$ a $\mathrm{r} \mathrm{o}$ & 373,91 & 496,77 & 352,4 & 1506,46 \\
\hline 12 & Deli Serdang & 19985,3 & 38894,8 & 27983 & 120301 \\
\hline 13 & Langkat & 4837,63 & 4953,3 & 5041,99 & 20444,8 \\
\hline 14 & Nias Selatan & 1,33 & 3,18 & 71,82 & 645,62 \\
\hline 15 & Humbang Hasundutan & 130,78 & 129,18 & 16,53 & 860,83 \\
\hline 16 & Pakpak Bharat & 0 & 0 & 0 & 0 \\
\hline 17 & Samosir & 20,49 & 13,75 & 0 & 0 \\
\hline 18 & Serdang Bedagai & 5998,8 & 7343,24 & 4622,35 & 17216,7 \\
\hline 19 & Batubara & 46515,8 & 36741,7 & 10694,3 & 5165 \\
\hline 20 & Padang Lawas Utara & 4277,87 & 4692,34 & 2695,93 & 2367,29 \\
\hline 21 & Padang Lawas & 4253,95 & 5776,05 & 4934,55 & 1936,87 \\
\hline 22 & Labuhan Batu Selatan & 7741,65 & 8412,75 & 10475,7 & 5380,21 \\
\hline 23 & Labuhan Batu Utara & 3476,36 & 3919,23 & 4555,39 & 4949,79 \\
\hline 24 & Nias Utara & 5,72 & 5,05 & 17,06 & 430,42 \\
\hline 25 & Nias Barat & 0 & 0 & 0 & 0 \\
\hline 26 & $\mathrm{Sibolga}$ & 0,63 & 0,76 & 0,88 & 215,21 \\
\hline 27 & Tanjungbalai & 1958,43 & 2049,65 & 1663,74 & 4734,58 \\
\hline 28 & Pematangsiantar & 3977,19 & 4325,98 & 4903,24 & 7101,87 \\
\hline 29 & Tebing Tinggi & 1899,5 & 1437,07 & 815,22 & 4088,96 \\
\hline 30 & Med a n & 136368 & 74190,6 & 57236,8 & 70588,3 \\
\hline 31 & $\mathrm{~B} \mathrm{in} \mathrm{ja} \mathrm{i}$ & 102,17 & 111,77 & 110,09 & 4734,58 \\
\hline 32 & Padangsidimpuan & 177,12 & 179 & 155,05 & 645,62 \\
\hline 33 & Gunungsitoli & 1,2 & 0,85 & 1,03 & 1291,25 \\
\hline
\end{tabular}

Sumber: BPS Indonesia

\subsection{Centroid Data}

Di dalam metode K-Means adapun penentuan cluster yang diinginkan. Penentuan cluster akan dibagi menjadi 2 titik yaitu tingkat tinggi (C1) dan tingkat rendah (C2). (C1) di dapat dari nilai maksimal suatu kriteria dan (C2) di dapat dari hasil nilai 
terendah dari suatu kriteria. Nilai kriteria tersebut dapat dilihat pada tabel 2 berikut ini:

Tabel 2. Centoid Awal

\begin{tabular}{lrrrr}
\hline & $\mathrm{a}$ & $\mathrm{b}$ & $\mathrm{c}$ & $\mathrm{d}$ \\
\hline $\mathrm{C} 1$ & 136368,1 & 74190,61 & 57236,79 & 120301,4 \\
$\mathrm{C} 2$ & 0 & 0 & 0 & 0 \\
\hline
\end{tabular}

Keterangan:

$\mathrm{a}=2013$

$\mathrm{b}=2014$

$\mathrm{c}=2015$

$\mathrm{d}=2016$

\subsection{Clustering Data}

Setelah didapat 2 titik centroid dari data yang ada selanjutnya akan melakuka proses iterasi 1 menggunakan 2 centroid data sebelumnya yang sudah ditentukan. Cluster tingkat tinggi (C1) ada 2 kabupaten/kota. Cluster tingkat rendah (C2) ada 31 kabupaten/kota lainnya. Hasil dari proses iterasi 1 bisa dilihat pada tabel 3 dan tabel 4 berikut ini:

Tabel 3. Perhitungan jarak pusat cluster

\begin{tabular}{|c|c|c|c|c|c|c|c|c|}
\hline No & Kabupaten/Kota & 2013 & 2014 & 2015 & 2016 & c1 & c2 & $\begin{array}{c}\text { Jarak } \\
\text { Terpendek }\end{array}$ \\
\hline 1 & $\mathrm{Ni}$ a $\mathrm{s}$ & 0 & 0 & 0 & 0 & 204570,2 & 0 & 0 \\
\hline 2 & Mandailing Natal & 1304,07 & 1742,7 & 1629,39 & 2152,08 & 201351,5 & 3467,559 & 3467,559 \\
\hline 3 & Tapanuli Selatan & 1065,5 & 916,73 & 1134,12 & 1076,04 & 202578,5 & 2102,326 & 2102,326 \\
\hline 4 & Tapanuli Tengah & 980,93 & 888,08 & 939,23 & 2797,71 & 201691,6 & 3234,23 & 3234,23 \\
\hline 5 & Tapanuli Utara & 163,72 & 413,49 & 343,93 & 645,62 & 203835,7 & 856,0907 & 856,0907 \\
\hline 6 & Toba Samosir & 804,59 & 1352,88 & 1226,78 & 2797,71 & 201561,5 & 3436,542 & 3436,542 \\
\hline 7 & Labuhan Batu & 4583,01 & 5191,18 & 4196,1 & 5595,42 & 195189,7 & 9842,17 & 9842,17 \\
\hline 8 & A s a h a n & 7057,51 & 9343,39 & 7483,84 & 29914 & 177684,1 & 32984,23 & 32984,23 \\
\hline 9 & Simalungun & 7142,76 & 6414,33 & 6038,57 & 12266,9 & 188641,3 & 16706,38 & 16706,38 \\
\hline 10 & $\mathrm{D}$ a i r i & 59,52 & 59,81 & 0 & 645,62 & 204129,8 & 651,1106 & 651,1106 \\
\hline 11 & $\mathrm{~K}$ a $\mathrm{r}$ o & 373,91 & 496,77 & 352,4 & 1506,46 & 203158,3 & 1667,392 & 1667,392 \\
\hline 12 & Deli Serdang & 19985,3 & 38894,8 & 27983 & 120301 & 125086,1 & 131025,6 & 125086,1 \\
\hline 13 & $\mathrm{~L}$ ang $\mathrm{kat}$ & 4837,63 & 4953,3 & 5041,99 & 20444,8 & 186520 & 22166,39 & 22166,39 \\
\hline 14 & Nias Selatan & 1,33 & 3,18 & 71,82 & 645,62 & 204169,1 & 649,6116 & 649,6116 \\
\hline 15 & Humbang Hasundutan & 130,78 & 129,18 & 16,53 & 860,83 & 203926,2 & 880,3933 & 880,3933 \\
\hline 16 & Pakpak Bharat & 0 & 0 & 0 & 0 & 204570,2 & 0 & 0 \\
\hline 17 & Samosir & 20,49 & 13,75 & 0 & 0 & 204551,6 & 24,67595 & 24,67595 \\
\hline 18 & Serdang Bedagai & 5998,8 & 7343,24 & 4622,35 & 17216,7 & 186706,9 & 20191,29 & 20191,29 \\
\hline 19 & Batubara & 46515,8 & 36741,7 & 10694,3 & 5165 & 157792,4 & 60454,27 & 60454,27 \\
\hline 20 & Padang Lawas Utara & 4277,87 & 4692,34 & 2695,93 & 2367,29 & 197891,4 & 7293,17 & 7293,17 \\
\hline 21 & Padang Lawas & 4253,95 & 5776,05 & 4934,55 & 1936,87 & 197181,1 & 8919,646 & 8919,646 \\
\hline 22 & Labuhan Batu Selatan & 7741,65 & 8412,75 & 10475,7 & 5380,21 & 190433,7 & 16413,23 & 16413,23 \\
\hline 23 & Labuhan Batu Utara & 3476,36 & 3919,23 & 4555,39 & 4949,79 & 196671,3 & 8526,279 & 8526,279 \\
\hline 24 & Nias Utara & 5,72 & 5,05 & 17,06 & 430,42 & 204307 & 430,8255 & 430,8255 \\
\hline 25 & Nias Barat & 0 & 0 & 0 & 0 & 204570,2 & 0 & 0 \\
\hline 26 & $\mathrm{Sibolga}$ & 0,63 & 0,76 & 0,88 & 215,21 & 204442,8 & 215,2141 & 215,2141 \\
\hline 27 & Tanjungbalai & 1958,43 & 2049,65 & 1663,74 & 4734,58 & 199284,6 & 5763,748 & 5763,748 \\
\hline 28 & Pematangsiantar & 3977,19 & 4325,98 & 4903,24 & 7101,87 & 194836,7 & 10440,81 & 10440,81 \\
\hline 29 & Tebing Tinggi & 1899,5 & 1437,07 & 815,22 & 4088,96 & 200159 & 4801,817 & 4801,817 \\
\hline 30 & Med a n & 136368 & 74190,6 & 57236,8 & 70588,3 & 49713,11 & 179886,8 & 49713,11 \\
\hline 31 & $\mathrm{~B}$ i n j a i & 102,17 & 111,77 & 110,09 & 4734,58 & 201681 & 4738,28 & 4738,28 \\
\hline 32 & Padangsidimpuan & 177,12 & 179 & 155,05 & 645,62 & 203964,5 & 710,1255 & 710,1255 \\
\hline 33 & Gunungsitoli & 1,2 & 0,85 & 1,03 & 1291,25 & 203812,2 & 1291,251 & 1291,251 \\
\hline
\end{tabular}


Berdasarkan hasil perhitungan jarak pusat cluster pada tabel 3, dapat diambil pengelompokan untuk 1 iterasi seperti yang ditunjukan pada tabel berikut:

Tabel 4. Pengelompokan Iterasi 1

\begin{tabular}{|c|c|c|c|}
\hline no & Kabupaten/Kota & $\mathrm{c} 1$ & $\mathrm{c} 2$ \\
\hline 1 & $\mathrm{Ni}$ a $\mathrm{s}$ & & 1 \\
\hline 2 & Mandailing Natal & & 1 \\
\hline 3 & Tapanuli Selatan & & 1 \\
\hline 4 & Tapanuli Tengah & & 1 \\
\hline 5 & Tapanuli Utara & & 1 \\
\hline 6 & Toba Samosir & & 1 \\
\hline 7 & Labuhan Batu & & 1 \\
\hline 8 & A s a han & & 1 \\
\hline 9 & Simalungun & & 1 \\
\hline 10 & $\mathrm{D}$ a i r i & & 1 \\
\hline 11 & $\mathrm{~K}$ a $\mathrm{r}$ o & & 1 \\
\hline 12 & Deli Serdang & 1 & \\
\hline 13 & $\mathrm{~L}$ a $\mathrm{gk}$ at & & 1 \\
\hline 14 & Nias Selatan & & 1 \\
\hline 15 & Humbang Hasundutan & & 1 \\
\hline 16 & Pakpak Bharat & & 1 \\
\hline 17 & Samosir & & 1 \\
\hline 18 & Serdang Bedagai & & 1 \\
\hline 19 & Batubara & & 1 \\
\hline 20 & Padang Lawas Utara & & 1 \\
\hline 21 & Padang Lawas & & 1 \\
\hline 22 & Labuhan Batu Selatan & & 1 \\
\hline 23 & Labuhan Batu Utara & & 1 \\
\hline 24 & Nias Utara & & 1 \\
\hline 25 & Nias Barat & & 1 \\
\hline 26 & Sibolg a & & 1 \\
\hline 27 & Tanjungbalai & & 1 \\
\hline 28 & Pematangsiantar & & 1 \\
\hline 29 & Tebing Tinggi & & 1 \\
\hline 30 & Med a n & 1 & \\
\hline 31 & B i n jai & & 1 \\
\hline 32 & Padangsidimpuan & & 1 \\
\hline 33 & Gunungsitoli & & 1 \\
\hline
\end{tabular}

Proses terus melakukan iterasi sampai hasil dari iterasi tersebut sama dengan hasil iterasi sebelumnya. Pada kasus ini proses iterasi berhenti pada iterasii ke 2 . Pada iterasi ke -2 dilakukan proses pencarian centroid data yang dapat dilihat pada tabel 5 berikut :

Tabel 5. Centoid Akhir

\begin{tabular}{ccccc}
\hline & $\mathrm{a}$ & $\mathrm{b}$ & $\mathrm{c}$ & $\mathrm{d}$ \\
\hline C1 & 78176,71 & 56542,71 & 42609,87 & 155595,6 \\
C2 & 3513,296 & 3448,845 & 2390,941 & 4567,969 \\
\hline
\end{tabular}

Berikut adalah hasil dari proses iterasi terakhir pada perhitungan jarak pusat cluster yang dapat dilihat pada tabel berikut ini:

Tabel 6. Perhitungan jarak pusat cluster iterasi ke-2

\begin{tabular}{llrrrrrrr}
\hline No & Kabupaten/Kota & $\mathbf{2 0 1 3}$ & $\mathbf{2 0 1 4}$ & $\mathbf{2 0 1 5}$ & $\mathbf{2 0 1 6}$ & $\mathbf{c 1}$ & c2 & $\begin{array}{c}\text { Jarak } \\
\text { Terpendek }\end{array}$ \\
\hline 1 & N i a s & 0 & 0 & 0 & 0 & 187974,1 & 7128,865 & 7128,865 \\
2 & Mandailing Natal & 1304,07 & 1742,7 & 1629,39 & 2152,08 & 184761,3 & 3769,362 & 3769,362 \\
3 & Tapanuli Selatan & 1065,5 & 916,73 & 1134,12 & 1076,04 & 186110 & 5116,295 & 5116,295 \\
4 & Tapanuli Tengah & 980,93 & 888,08 & 939,23 & 2797,71 & 184770,8 & 4267,514 & 4267,514 \\
5 & Tapanuli Utara & 163,72 & 413,49 & 343,93 & 645,62 & 187169,5 & 6325,197 & 6325,197 \\
6 & Toba Samosir & 804,59 & 1352,88 & 1226,78 & 2797,71 & 184640,5 & 4027,312 & 4027,312
\end{tabular}




\begin{tabular}{|c|c|c|c|c|c|c|c|c|}
\hline No & Kabupaten/Kota & 2013 & 2014 & 2015 & 2016 & c1 & c2 & $\begin{array}{c}\text { Jarak } \\
\text { Terpendek }\end{array}$ \\
\hline 7 & Labuhan Batu & 4583,01 & 5191,18 & 4196,1 & 5595,42 & 178965,6 & 2914,494 & 2914,494 \\
\hline 8 & As a h a n & 7057,51 & 9343,39 & 7483,84 & 29914 & 155934,1 & 26751,89 & 26751,89 \\
\hline 9 & Simalungun & 7142,76 & 6414,33 & 6038,57 & 12266,9 & 171578,7 & 9723,445 & 9723,445 \\
\hline 10 & $\mathrm{D}$ a $\mathrm{i} \mathrm{r} \mathrm{i}$ & 59,52 & 59,81 & 0 & 645,62 & 187397,2 & 6671,997 & 6671,997 \\
\hline 11 & $\mathrm{~K}$ a $\mathrm{r}$ o & 373,91 & 496,77 & 352,4 & 1506,46 & 186342,6 & 5665,596 & 5665,596 \\
\hline 12 & Deli Serdang & 19985,3 & 38894,8 & 27983 & 120301 & 71814,41 & 124807,6 & 71814,41 \\
\hline 13 & Langkat & 4837,63 & 4953,3 & 5041,99 & 20444,8 & 166484,7 & 16220,94 & 16220,94 \\
\hline 14 & Nias Selatan & 1,33 & 3,18 & 71,82 & 645,62 & 187422,2 & 6705,942 & 6705,942 \\
\hline 15 & Humbang Has & 130,78 & 129,18 & 16,53 & 860,83 & 187164,9 & & \\
\hline 16 & Pakpa & 0 & 0 & 0 & 0 & & & \\
\hline 17 & Sam & 20,49 & 13,75 & 0 & 0 & & & \\
\hline 18 & Serd & 5998,8 & 7343,24 & 4622,35 & 17216,7 & & & \\
\hline 19 & Batub & 46515,8 & 36741,7 & 10694,3 & 5165 & 158 & 57 & 57 \\
\hline 20 & Padan & 4277,87 & 4692,34 & 2695,93 & 2367,29 & 182 & 265 & 356 \\
\hline 21 & Padar & 4253,95 & 5776,05 & 4934,55 & 1936,87 & 181 & 439 & 668 \\
\hline 22 & Labu & 7741,65 & 8412,75 & 10475,7 & 5380,21 & 175 & 104 & 8,35 \\
\hline 23 & Labul & 3476,36 & 3919,23 & 4555,39 & 4949,79 & 54,5 & 2247,944 & 2247,944 \\
\hline 24 & Nias & 5,72 & 5,05 & 17,06 & 430,42 & 187610,2 & 6849,63 & 6849,63 \\
\hline 25 & Nias B & 0 & 0 & 0 & 0 & 187974,1 & 7128,865 & 7128,865 \\
\hline 26 & $\mathrm{Sibo}$ & 0,63 & 0,76 & 0,88 & 215,21 & 187795,3 & 6991,925 & 6991,925 \\
\hline 27 & Tanjur & 1958,43 & 2049,65 & 1663,74 & 4734,58 & 182248 & 2220,796 & 2220,796 \\
\hline 28 & Pematangsiantar & 3977,19 & 4325,98 & 4903,24 & 7101,87 & 178057,1 & 3703,629 & 3703,629 \\
\hline 29 & Tebing Tinggi & 1899,5 & 1437,07 & 815,22 & 4088,96 & 183182,7 & 3060,053 & 3060,053 \\
\hline 30 & Medan & 136368 & 74190,6 & 57236,8 & 70588,3 & 105536,1 & 173267,3 & 105536,1 \\
\hline 31 & $\mathrm{Binjai}$ & 102,17 & 111,77 & 110,09 & 4734,58 & 183971,1 & 5291,681 & 5291,681 \\
\hline 32 & Padan & 177,12 & 179 & 155,05 & 645,62 & 187277,1 & 6496,613 & 6496,613 \\
\hline 33 & Gunungsitoli & 1,2 & 0,85 & 1,03 & 1291,25 & 186905,7 & 6377,464 & 6377,464 \\
\hline
\end{tabular}

Berdasarkan hasil perhitungan jarak pusat cluster pada iterasi ke-2 sama dengan pengelompokan pada iterasi ke -1 yang ditunjukan pada tabel berikut:

Tabel 7. Pengelompokan Iterasi 2

\begin{tabular}{|c|c|c|c|}
\hline no & Kabupaten/Kota & $\mathrm{c} 1$ & $\mathrm{c} 2$ \\
\hline 1 & $\mathrm{Nias}$ & & 1 \\
\hline 2 & Mandailing Natal & & 1 \\
\hline 3 & Tapanuli Selatan & & 1 \\
\hline 4 & Tapanuli Tengah & & 1 \\
\hline 5 & Tapanuli Utara & & 1 \\
\hline 6 & Toba Samosir & & 1 \\
\hline 7 & Labuhan Batu & & 1 \\
\hline 8 & As ah a n & & 1 \\
\hline 9 & Simalungun & & 1 \\
\hline 10 & $\mathrm{D}$ a i r i & & 1 \\
\hline 11 & $\mathrm{~K}$ a $\mathrm{ro}$ & & 1 \\
\hline 12 & Deli Serdang & 1 & \\
\hline 13 & Langkat & & 1 \\
\hline 14 & Nias Selatan & & 1 \\
\hline 15 & Humbang Hasundutan & & 1 \\
\hline 16 & Pakpak Bharat & & 1 \\
\hline 17 & Samosir & & 1 \\
\hline 18 & Serdang Bedagai & & 1 \\
\hline 19 & Batubara & & 1 \\
\hline 20 & Padang Lawas Utara & & 1 \\
\hline 21 & Padang Lawas & & 1 \\
\hline 22 & Labuhan Batu Selatan & & 1 \\
\hline 23 & Labuhan Batu Utara & & 1 \\
\hline 24 & Nias Utara & & 1 \\
\hline 25 & Nias Barat & & 1 \\
\hline 26 & Sibolga & & 1 \\
\hline 27 & Tanjungbalai & & 1 \\
\hline
\end{tabular}




\begin{tabular}{|c|c|c|}
\hline 28 & Pematangsiantar & \\
\hline 29 & Tebing Tinggi & \\
\hline 30 & Medan & 1 \\
\hline 31 & $\mathrm{Binjai}$ & \\
\hline 32 & Padangsidimpuan & \\
\hline 33 & Gunungsitoli & \\
\hline
\end{tabular}

\section{Cluster Model}

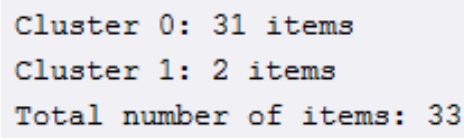

Gambar 2. Hasil dengan menggunakan software RapiMiner

Hasil perhitungan menggunakan 2 centroid data pada iterasi ke - 2 ternyata sama dengan hasil perhitungan pada iterasi ke -2 dan hal ini menandakan bahwa proses telah selesai.Dari proses tersebut didapat dari 33 kabupaten/kota bahwa terdapat 2 kabupaten/kota yang tergolong dalam hasil industri tingkat tinggi lalu ada 31 kabupaten/kota yang tergolong dalam populasi tingkat rendah lainnya.

\section{Kesimpulan}

Dalam menentukan tingkat hasil industry besar.sedang berdasarkan kabupaten/kota dapat menggunakan clustering dalam penghitungannya. Data tersebut diolah dengan bantuan software MS. Excel dalam proses perhitungannya. Ditetapkan 2 cluster antaralain: cluster tingkat tinggi dan rendah. Sehingga dapat diperoleh hasil dari nilai centroid tersebut bahwa terdapat 2 kabupaten/kota yang tergolong tingkat tinggi dan 31 kabupaten/kota tergolong rendah. Hasil dari penelitian ini bisa jadi masukan dan suatu informasi kepada pemerintah disetiap wilayah untuk memberi informasi tentang data pendapatan industri berdasarkan nilai tambah yang selanjutnya data tersebuat bisa digunakan jika sewaktu-waktu dibutuhkan.

\section{Daftar Pustaka}

[1] W. Katrina, H. J. Damanik, F. Parhusip, D. Hartama, A. P. Windarto, and A. Wanto, "C.45 Classification Rules Model for Determining Students Level of Understanding of the Subject," J. Phys. Conf. Ser., vol. 1255, no. 12005, pp. 1-7, 2019, doi: 10.1088/1742-6596/1255/1/012005.

[2] M. Widyastuti, A. G. Fepdiani Simanjuntak, D. Hartama, A. P. Windarto, and A. Wanto, "Classification Model C.45 on Determining the Quality of Custumer Service in Bank BTN Pematangsiantar Branch,” J. Phys. Conf. Ser., vol. 1255, no. 12002, pp. 1-6, 2019, doi: 10.1088/1742-6596/1255/1/012002.

[3] Sudirman, A. P. Windarto, and A. Wanto, "Data mining tools | rapidminer: Kmeans method on clustering of rice crops by province as efforts to stabilize food crops in Indonesia," IOP Conf. Ser. Mater. Sci. Eng., vol. 420, no. 1, 2018, doi: 10.1088/1757-899X/420/1/012089.

[4] R. W. Sari, A. Wanto, and A. P. Windarto, "Implementasi Rapidminer Dengan Metode K-Means (Study Kasus: Imunisasi Campak Pada Balita Berdasarkan Provinsi)," KOMIK (Konferensi Nas. Teknol. Inf. dan Komputer), vol. 2, no. 1, pp. 224-230, 2018, doi: 10.30865/komik.v2i1.930.

[5] N. Rofiqo, A. P. Windarto, and D. Hartama, "Penerapan Clustering Pada Penduduk Yang Mempunyai Keluhan Kesehatan Dengan Datamining K-Means," KOMIK (Konferensi Nas. Teknol. Inf. dan Komputer), vol. 2, no. 1, pp. 216-223, 
2018, doi: 10.30865/komik.v2i1.929.

[6] M. G. Sadewo, A. P. Windarto, and A. Wanto, "Penerapan Algoritma Clustering Dalam Mengelompokkan Banyaknya Desa/Kelurahan Menurut Upaya Antisipasi/ Mitigasi Bencana Alam Menurut Provinsi Dengan K-Means," KOMIK (Konferensi Nas. Teknol. Inf. dan Komputer), vol. 2, no. 1, pp. 311-319, 2018, doi: 10.30865/komik.v2i1.943.

[7] D. Hartama, A. Perdana Windarto, and A. Wanto, "The Application of Data Mining in Determining Patterns of Interest of High School Graduates," J. Phys. Conf. Ser., vol. 1339, no. 1, 2019, doi: 10.1088/1742-6596/1339/1/012042.

[8] D. R. Sari, N. Rofiqo, D. Hartama, A. P. Windarto, and A. Wanto, "Analysis of the Factors Causing Lazy Students to Study Using the ELECTRE II Algorithm," J. Phys. Conf. Ser., vol. 1255, no. 1, 2019, doi: 10.1088/1742-6596/1255/1/012007.

[9] R. W. Sari, A. P. Windarto, S. P. Keputusan, P. Kreatifitas, M. Pkm, and A. D. A. N. Pembahasan, "Penerapan Electree Pada Seleksi Proposal Program Kreativitas Mahasiswa ( PKM ) di STIKOM Tunas Bangsa," in Seminar Nasional Teknologi Komputer \& Sains (SAINTEKS) SAINTEKS 2019, 2019, pp. 800-806.

[10] F. Syahputra, M. Mesran, I. Lubis, and A. P. Windarto, "Sistem Pendukung Keputusan Pemilihan Guru Berprestasi Kota Medan Menerapkan Metode Preferences Selection Index (Studi Kasus: Dinas Pendidikan Kota Medan)," KOMIK (Konferensi Nas. Teknol. Inf. dan Komputer), vol. 2, no. 1, pp. 147-155, 2018, doi: 10.30865/komik.v2i1.921.

[11] P. P. P. A. N. W. F. I. R. H. Zer, Masitha, A. P. Windarto, and A. Wanto, "Analysis of the ELECTRE Method on the Selection of Student Creativity Program Proposals," J. Phys. Conf. Ser., vol. 1255, no. 1, 2019, doi: 10.1088/1742-6596/1255/1/012011.

[12] P. P. P. A. N. W. F. I. R. H. Zer, D. Hartama, and A. P. Windarto, "Analisis Komparasi Metode AHP dan TOPSIS dalam Pemilihan Asuransi Kategori Kesehatan Terbaik PT . Prudential," in Seminar Nasional Sains \& Teknologi Informasi (SENSASI) SENSASI 2019, 2018, pp. 427-432.

[13] M. Widyastuti, F. R. S. Samosir, A. P. Windarto, and D. Hartama, "Implementasi Metode Promethee Dalam Pemilihan Kenaikan Jabatan Sous Chef Menjadi Chef," Teknol. Komput. Sains, vol. 1, no. 1, pp. 807-812, 2019.

[14] S. Sundari, Karmila, M. N. Fadli, D. Hartama, A. P. Windarto, and A. Wanto, "Decision Support System on Selection of Lecturer Research Grant Proposals using Preferences Selection Index," J. Phys. Conf. Ser., vol. 1255, no. 1, pp. 1-8, 2019, doi: 10.1088/1742-6596/1255/1/012006.

[15] P. Alkhairi, L. P. Purba, A. Eryzha, A. P. Windarto, and A. Wanto, "The Analysis of the ELECTREE II Algorithm in Determining the Doubts of the Community Doing Business Online," J. Phys. Conf. Ser., vol. 1255, no. 1, 2019, doi: 10.1088/1742-6596/1255/1/012010.

[16] D. N. Batubara, D. R. Sitorus P, and A. P. Windarto, "Penerapan Metode PROMETHEE II Pada Pemilihan Situs Travel Berdasarkan Konsumen," J. Sisfokom (Sistem Inf. dan Komputer), vol. 8, no. 1, pp. 46-52, 2019, doi: 10.32736/sisfokom.v8i1.598.

[17] K. Fatmawati et al., "Analysis of Promothee II Method in the Selection of the Best Formula for Infants under Three Years," J. Phys. Conf. Ser., vol. 1255, no. 1, 2019, doi: 10.1088/1742-6596/1255/1/012009.

[18] T. Imandasari, A. P. Windarto, and D. Hartama, "Seminar Nasional Teknologi Komputer \&amp; Sains (SAINTEKS) Analisis Metode MAUT Pada Pemilihan Deodorant," in Seminar Nasional Teknologi Komputer \& Sains (SAINTEKS) SAINTEKS 2019, 2019, pp. 736-739.

[19] K. F. Irnanda, F. N. Arifah, M. R. Raharjo, A. Arifin, and A. P. Windarto, "The 
selection of Calcium Milk Products that are appropriate for advanced age using PROMETHEE II Algorithm," J. Phys. Conf. Ser., vol. 1381, no. 1, 2019, doi: 10.1088/1742-6596/1381/1/012070.

[20] T. Imandasari, M. G. Sadewo, A. P. Windarto, A. Wanto, H. O. Lingga Wijaya, and R. Kurniawan, "Analysis of the Selection Factor of Online Transportation in the VIKOR Method in Pematangsiantar City," J. Phys. Conf. Ser., vol. 1255, no. 12008, pp. 1-7, 2019, doi: 10.1088/1742-6596/1255/1/012008.

[21] T. Imandasari and A. P. Windarto, "Penerapan Metode VIKOR Pada Pemilihan Popok Bayi Berdasarkan Jenis Kulit,” Semin. Nas. Sains Teknol. Inf., pp. 215-220, 2018.

[22] Hamdani, "Sistem Pakar Untuk Diagnosa Penyakit Mata Pada Manusia," vol. 5, no. 2, pp. 13-21, 2010.

[23] A. P. Windarto, M. R. Lubis, and Solikhun, "Implementasi Jst Pada Prediksi Total Laba Rugi Komprehensif Bank Umum Konvensional Dengan Backpropagation," J. Teknol. Inf. dan Ilmu Komput., vol. 5, no. 4, pp. 411-418, 2018, doi: 10.25126/jtiik.201854767.

[24] A. P. Windarto, M. R. Lubis, and Solikhun, "Model Arsitektur Neural Network Dengan Backpropogation Pada Prediksi Total Laba Rugi Komprehensif Bank Umum Konvensional," Kumpul. J. Ilmu Komput., vol. 5, no. 2, pp. 147-158, 2018.

[25] A. P. Windarto, L. S. Dewi, and D. Hartama, "Implementation of Artificial Intelligence in Predicting the Value of Indonesian Oil and Gas Exports With BP Algorithm," Int. J. Recent Trends Eng. Res., vol. 3, no. 10, pp. 1-12, 2017, doi: 10.23883/IJRTER.2017.3482.J5BBS.

[26] Sumijan, A. P. Windarto, A. Muhammad, and Budiharjo, "Implementation of Neural Networks in Predicting the Understanding Level of Students Subject," Int. J. Softw. Eng. Its Appl., vol. 10, no. 10, pp. 189-204, 2016.

[27] Budiharjo, T. Soemartono, A. P. Windarto, and T. Herawan, "Predicting tuition fee payment problem using backpropagation neural network model," Int. J. Adv. Sci. Technol., vol. 120, pp. 85-96, 2018, doi: 10.14257/ijast.2018.120.07.

[28] Budiharjo, T. Soemartono, A. P. Windarto, and T. Herawan, "Predicting School Participation in Indonesia using Back-Propagation Algorithm Model," Int. J. Control Autom., vol. 11, no. 11, pp. 57-68, 2018.

[29] C. C. Lee, "Fuzzy Logic in Control Systems : Fuzzy," no. 2, 1990.

[30] D. N. Batubara, A. P. Windarto, D. Hartama, and H. Satria, "Analisis Metode KMEANS Pada Pengelompokan Keberadaan Area Resapan Air Menurut Provinsi," no. x, pp. 345-349, 2019.

[31] Cooper, “No 主観的健康感を中心とした在宅高齢者における 健康関連指標 に関する共分散構造分析Title,”pp. 5-10, 2019. 